\title{
CIDADE, PATRIMÓNIO E CENTROS HISTÓRICOS: política e reabilitação urbana em Coimbra
}

\author{
city, heritage and historic downtown: policy and urban renewal in Coimbra
}

\author{
Norberto Santos * \\ Liliana Azevedo **
}

\begin{abstract}
Resumo
O centro histórico apresenta um sentido dual. Primeiramente é campo de proteção de uma população que continua presente e tem nele o seu espaço de vida. Seguidamente é símbolo público resultado das intervenções que lhe vêm transmitindo uma crescente capacidade imagética, expressando manifestações de grandiosidade e evidenciando motivações de atração para uma população forasteira. Se bem que, seja um espaço onde é comum encontrar situações de deterioração do património edificado e fuga residencial para a periferia, pretende-se efetuar a identificação de reabilitações que têm facilitado a patrimonialização e a transformação do Centro Histórico num produto turístico associado à qualidade de vida dos residentes. Usando exemplos de intervenções e reabilitações diversas no território português, centraremos a abordagem aqui efetuada nas ações, projetos, iniciativas e parcerias do Gabinete para o Centro Histórico da Câmara Municipal de Coimbra, salientando algumas intervenções inovadoras, casos de sucesso, problemas organizativos e potencialidades resultantes das ações integradas de diferentes parceiros.
\end{abstract}

Palavras-chave: Centro históricos, Reabilitação urbana, Atividades culturais e de lazer, Coimbra.

\begin{abstract}
Historic downtown has achieved a double meaning. First, it has to consider the protection of its endogenous population with its lived space. Secondly, it is a public symbol resulting from the constant interventions which endow it with an image of grandiosity and is an attraction for visitors.Although, historical centers are places where we can attest to the deterioration of material heritage, rehabilitation has assisted in transforming these areas into a touristic commodity. The present paper analyses the numerous rehabilitation activities carried out by the Bureau for the Historical Centre of the city of Coimbra, highlighting some of its most innovative aspects, success stories, organizational challenges, and potential results of integrating different partners.
\end{abstract}

Key words: Historic downtown, Urban renewal, Cultural activities and leisure, Coimbra.

\begin{abstract}
Résumé
Le centre-ville historique presente une double valeur. Premièrement, il doit assurer la protection de sa population endogène, qui y trouve son espace vécu. Deuxièmement, il constitue un symbole public résultant des interventions constantes qui l'agrandissent et attirent les visiteurs. Bien que les centres historiques soient des endroits où l'on peut trouver des situations de dégradation du patrimoine matériel, on prétend identifier des situations de réhabilitation qui rendent plus facile leur patrimonialisation et qui permettent à ces zones de devenir des produits touristiques auxquels est associé la qualité de vie des gens qui y résident. Malgré tout, nous pouvons encore observer l'inefficacité de la programmation des investissements publics dans les infrastructures collectives et les services publics. En outre, l'absence de la culture civique orientée vers l'aménagement du territoire rend plus difficile la coordonnation des initiatives entre les principaux acteurs institutionnels. Le présent document analyse les nombreuses activités de réhabilitation menées par le Bureau pour le Centre historique de la ville de Coimbra, en soulignant certains de leurs aspects les plus innovateurs, les réussites, les défis organisationnels et les résultats potentiels de l'intégration des différents partenaires. Mots-clés:
\end{abstract}

Mots-Clés: Centre-ville historique, Rénovation urbaine, Activités culturelles et de loisirs, Coimbra.

(*) Prof. Dr. do Centro de Estudos de Geografia e Ordenamento do Território, Centro de Estudos de Geografia e Ordenamento do Território, Departamento de Geografia, Universidade de Coimbra, CEP: 3004-530, Coimbra - Portugal, Tél: (239) 857000 norgeo@ci.uc.pt

(**) Pós-graduanda em Tecnologias de Informação Geográfica (TIG), do Departamento de Geografia e do Departamento de Matemática da Universidade de Coimbra. Técnica do Gabinete de Informação Geográfica da Câmara Municipal de Coimbra, Praça 8 de Maio, CEP 3000-300, Coimbra - Portugal, Tel: (239)857500 - liliana.azevedo@cm-coimbra.pt 


\section{INTRODUÇÃO}

A autarquia é co-responsável pela organização espacial urbana e vai promover, na sociedade que regula, a participação social, económica, política e cultural de stakeholders diversos. Desta forma consegue:

. dar melhor resposta à influência de um mercado neoliberal omnipresente,

- promover a comunicação e imagem através do marketing territorial, num esforço endógeno de divulgação de recursos, atrações e produtos, e

-.dar expressão às atuações locais de agentes que precisam de estar bem preparados e apoiados em estruturas de relação ancoradas socioeconomicamente para atingir um ciclo virtuoso resultante do bom planeamento, da qualidade do ordenamento, da qualidade de vida da população, do posicionamento da cidade e das sinergias e complementaridades das redes em que integra

Assim sendo, a rede urbana é, pois, um elemento fundamental em todo o processo e a importância das cidades médias na estruturação das relações entre cidades, na sustentação das ligações entre áreas centrais e áreas periféricas, é fundamental. Como diz Reynaud (1981), dificilmente encontramos cidades que tenham uma função exclusiva de centro. A maior parte delas assume, em função da escala, dependendo da função central em análise, tomando em atenção as redes de relações (de complementaridade, de sinergia, ...) (CAMAGNI, 1992) que se valorizam, uma posição relativa de centro para alguns lugares e periferia para outros.

Em Portugal, o Prosiurb (Programa de Consolidação do Sistema Urbano Nacional) (excluindo áreas metropolitanas), em 1994, foi essencial na implementação deste conceito, na procura da redução das assimetrias regionais e promoção do desenvolvimento. As cidades elegíveis seriam aquelas com uma população superior a 10.000 habitantes, com um nível de equipamentos supraconcelhio , funcionando como centros alternativos às áreas metropolitanas e catalisadores de desenvolvimento das áreas envolventes, capazes de estruturar espaços sub-regionais (coesão e autonomia) e de integrar redes internacionais. Desta forma foram integradas no programa quarenta cidades médias, embora não utilizando o critério vulgarmente usado na Europa (aglomerados entre 50.000 a 500.000 habitantes). A cidade de Coimbra foi integrada neste grupo, indo ao encontro da definição efetuada por Lajugie (1973), que referia como limiares superiores e inferiores, respetivamente, os 20.000 e os 200.000 habitantes. Como seria de esperar, os critérios quantitativos foram conjugados com outros qualitativos. Neste sentido, valorizaram-se 4 características principais: o estilo de vida urbano (nem rural nem metropolitano), a presença de equipamentos urbanos para satisfação da maior parte das necessidades da população, os contactos e relações pessoais significativas e as comunidades locais bem definidas.

Este Programa obriga ao aparecimento dos Planos Estratégicos e à ratificação dos Planos Diretores Municipais e dos Planos de Pormenor, tal como promoveu o aparecimento do PROCOM (Programa de Apoio à Modernização do Comércio) e do Polis (Programa de Requalificação Urbana e Valorização Ambiental de Cidades). Hoje o PNPOT (2007) define as opções estratégicas de política urbana afirmando a necessidade de decidir entre completar ou estender (o crescimento urbano); compactar ou diversificar (densidades, atividades); revitalizar o centro ou favorecer o policentrismo; diversificar e/ou misturar (atividades) para reequilíbrio territorial. Afirma ainda a importância em construir continuidades e estruturas de sustentabilidade com o espaço coletivo e com os espaços naturais ("sistemas ecológicos e paisagem enquadrando a diversidade das formas de urbanização"). Tudo isto se integra numa diversidade de redes de relação e organização territorial em que as cidades são o elemento central. Temos uma organização igual à que é interpretada por Ascher (1998) em que a forma das redes de estrelas substitui a da teia de aranha hierarquizada 
dando assim origem a um modelo de eixos e raios criado por lógicas de trânsito dos fluxos de bens, de pessoas e de informações.

Coimbra (Figura 1) surge, nesta organização, como a única cidade, fora da área de influência direta das grandes áreas metropolitanas, com uma rede bem estruturada para áreas de influências especializadas e muito especializadas, tanto em termos de Índice de Centralidade como de Interações. Coimbra "é a única cidade de dimensão assinalável (mais de cem mil habitantes) que - fora das áreas metropolitanas ou da sua zona de influência imediata - estrutura e polariza um espaço urbano relevante, não tributário de Lisboa e do Porto" (REIS, 2009).

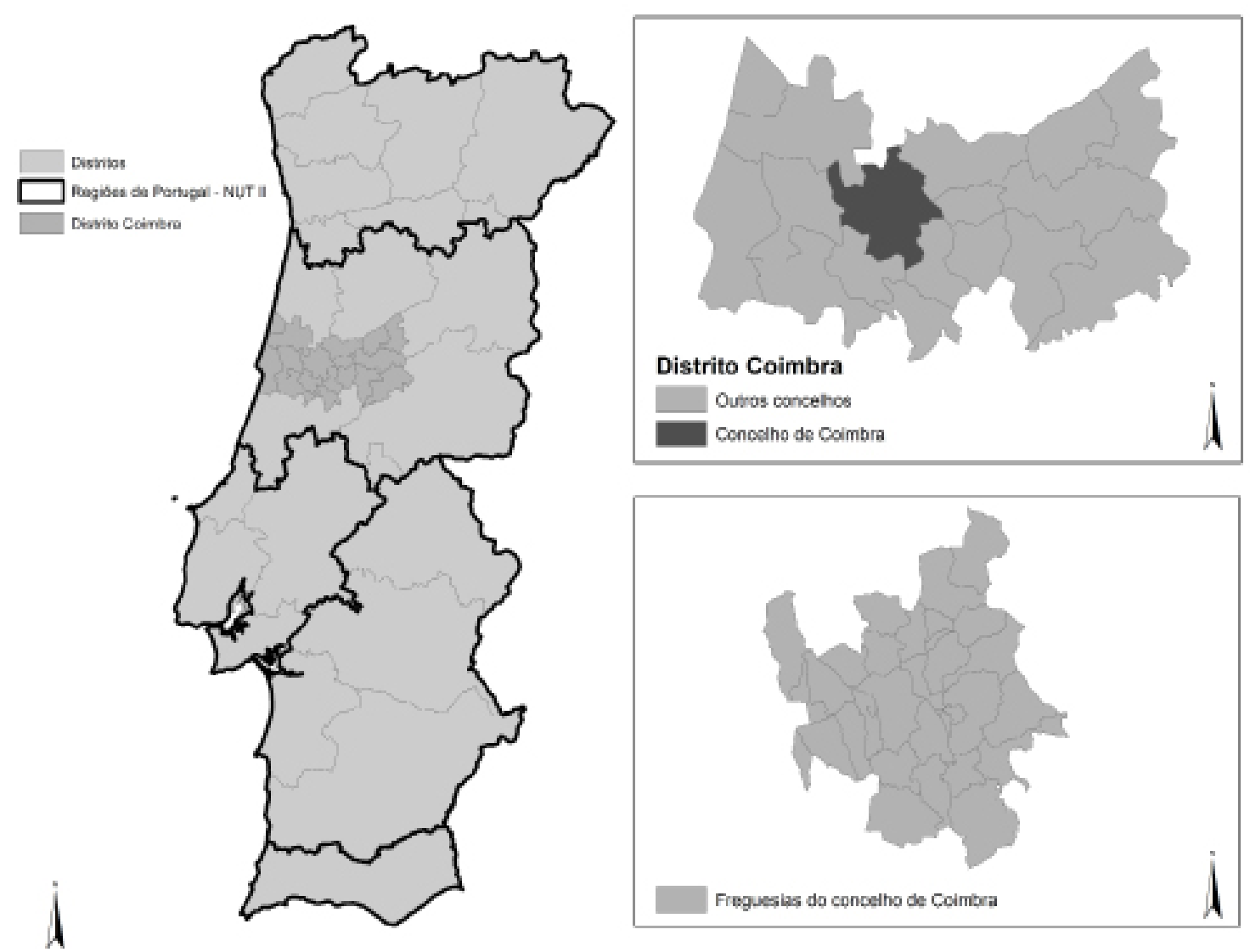

Figura 1 - Localização geográfica do Concelho de Coimbra à escala nacional Fonte: Adaptação própria. Atlas do Ambiente e CMC

A cidade média promove a qualidade de vida urbana. A medida desta qualidade de vida depende das condições de existência de cada homem e das suas aspirações (...) nos domínios social e ambiental, com a identificação dos elementos que constituem as condições de vida, de saúde, de inserção na vida ativa, de utilização do tempo livre, de vida familiar, conjuntamente com os elementos económicos sobre os rendimentos, os consumos e os patrimónios (TOBELEM-ZANIN, 1995).

De acordo com Costa (2002), são precisas novas interpretações concetuais que reconheçam “a heterogeneidade dos modelos de desenvolvimento económico e de diferentes modos de regulação e a sua influência na organização do território" (COSTA, 2002: 121). Este propósito ganha significado na asserção da cidade média enquanto santuário de um mix de modos de relação social, de regulação e institucionais dificilmente encontráveis noutros centros populacionais. A estes se juntam recursos e qualidades de acessibilidade, sustentabilidade e criatividade permitidos pela descentralização funcional e técnica, logo que associados a um processo de política de desenvolvimento territorial. 


\section{O LUGAR DO CENTRO HISTÓRICO URBANO: elemento estratégico de uma política participativa e sustentável}

A cidade tem surgido como território motivador de novas experiências e participações turísticas. Entendendo o turismo como um produto é preciso criar modos de consumo que se ajustem a um conjunto de características dominantes como são: o aumento do poder de compra, a mobilidade acrescida, maior informação, mas também preferências mais voláteis e consumistas, ainda assim em contraponto com a sua capacidade de influenciar a oferta e a procura de identidade que implica a segmentação do mercado e a fuga à massificação. Daí que a procura de turismo e lazeres alternativos seja uma tendência dominante através do cineturismo, do garden tourism, do pedestrianismo urbano, do lazer ativo, das rotas de património, do turismo arqueológico, do turismo de congressos, do turismo de eventos, do turismo educativo, do turismo gastronómico, do turismo literário, da recriação histórica, entre outros.

Esta valência turística e a procura de oferecer à população residente qualidade de vida, no lugar ou em outros lugares da cidade, tem dado expressão, como já foi abordado acima, ao ordenamento do território da cidade e dos centros históricos. Aqui os problemas fulcrais estão bem identificados: despovoamento e fragilização demográfica e socioeconómica; degradação da qualidade de muitas áreas residenciais, persistência de importantes segmentos de população sem acesso condigno à habitação, agravando as disparidades sociais intraurbanas; problemas de programação do investimento público em infraestruturas e equipamentos coletivos; ausência de uma cultura cívica valorizadora do ordenamento do território baseada no conhecimento rigoroso dos problemas, na participação dos cidadãos e na capacitação técnica das instituições e dos agentes mais diretamente envolvidos, dificuldade de coordenação entre os principais atores institucionais, públicos e privados.

O urbanismo comercial tem tido um papel muito importante na construção de uma cidade atrativa e identitária, conjugando um planeamento participativo com a qualidade e diversidade da oferta, tanto para o residente como para o visitante. O incremento deste urbanismo surge associado ao aumento da importância do comércio no que diz respeito à produção e ao consumo e conjuga-se com o interesse crescente pelo ordenamento do território por parte da administração central e local, condicionado pelas transformações urbanas e no aparelho comercial que têm levado os planeadores a atribuir ao comércio e serviços um papel mais interventivo no desenvolvimento económico e social.

Balsas (1999) (2002) teve um papel precursor na difusão dos projetos com impacto ao nível do ordenamento comercial e surgem mesmo algumas experiências interessantes no âmbito do território português. As Áreas de Desenvolvimento Económico (Business Improvement Districts), originárias dos Estados Unidos da América (EUA) materializam-se em empresas com a função de fornecerem serviços suplementares para uma área geográfica através da tributação das atividades comerciais e o assegurar da sua manutenção, segurança e marketing, sendo constituídas e geridas pelos proprietários dessa área específica. Outro tipo de projeto é o denominado Programa da Rua Central (Main Street Program), também originários dos EUA e associado a uma estratégia de revitalização comercial integrada juntando desenvolvimento económico com preservação histórica do centro das cidades, claramente ajustado ao tema central deste texto. Procurando atingir uma reestruturação económica e organizacional, visa a promoção e a recriação do lugar pela intervenção ao nível do design. $\mathrm{O}$ objetivo principal do Programa da Rua Central é criar um meio agradável e atrativo que estimule as pessoas a voltar ao centro e os visitantes a terem-no como âncora do seu itinerário na cidade. Um outro tipo de projeto referido por Balsas (1999) é a Gestão do Centro de Cidade (Town Centre Management - TCM), este originário do Reino Unido e também de grande pertinência quanto à sua aplicabilidade em centros históricos urbanos. Efetivamente, enraizada nas agendas do planeamento urbano das cidades da Europa Ocidental, no sentido da revitalização dos centros históricos, define uma estrutura organizacional com o estabelecimento de parcerias de cooperação entre os sectores público e privado com o intuito de melhorar e/ou preservar da qualidade do centro das cidades. 
Este tipo de programa esteve na base de um projeto com significado na valorização dos centros históricos das nossas cidades e que criou o conceito de Gestor de Centro Urbano, que teve a parceria formativa do Centro de Formação Profissional Para o Comércio e Afins e que levou a diversas cidades portuguesas técnicos e equipas com a orientação específica de revitalizarem os centros urbanos, dando-lhes uma nova vida. Os centros históricos urbanos são espaços em mutação, como se pode compreender pelas referências efetuadas e pelas intervenções que nesses espaços vão sendo efetuadas pelas denominadas Sociedades de Reabilitação Urbana.

Hoje, joga-se o prestígio ambiental e arquitetónico do espaço construído dos centros históricos como forma de marketing urbano e cidades como Évora, Viseu, Guimarães, Porto, Lisboa, Guarda, Coimbra, entre muitas outras, encontram nestes lugares a disponibilidade de projeção do seu património construído, o incremento da facilidade de acesso para o conjunto de cidadãos residentes e visitantes, a atratividade da teatralização da vida urbana (a rua/espaço público), a expansão das funções de lazer e diversão, desenvolvimento de manifestações culturais e a identificação desses espaços como objeto de consumo em si mesmo, num mercado ávido de produtos alternativos, com a transformação do centro histórico em produto turístico.

\section{O CENTRO HISTÓRICO DE COIMBRA}

Encarados como repositórios e como propulsores de atividades culturais diversas, os centros históricos tornam-se objeto de uma idealização no âmbito das políticas urbanas.

O centro histórico de Coimbra está classificado em três graus de proteção, englobando áreas com diferentes tipologias de habitação, de ocupação dos espaços e com diferentes graus de complexidade, pelo que as intervenções, por si só, revelam-se específicas e singulares.

A cidade velha ou cidade antiga insere-se na área de proteção com grau 1 (Figura 2), que se estende numa área de 131,33 hectares e que, para além da Alta, onde o Gabinete para o Centro Histórico intervém mais diretamente, estão também incluídas a Baixa e, na margem esquerda do Mondego, Santa Clara.

A Câmara Municipal de Coimbra (CMC) tem vindo, de forma mais efetiva desde 1990, a efetuar a recuperação do seu património construído em especial do núcleo mais antigo da cidade (Alta e Baixa).

As ações promovidas até agora têm tido como orientação estratégica duas linhas estruturantes: reabilitação urbana (quer do ponto de vista do edificado, quer do ponto de vista social) e a manutenção das atividades económicas tradicionais da zona. Para este efeito a Autarquia promoveu três ações integradas para o seu núcleo urbano mais antigo: o PRAUD - Programa de Recuperação de Áreas Urbanas Degradadas; o projeto de revitalização da Baixinha: Programa de Apoio à Modernização do comércio na área central da cidade (PROCOM / URBCOM) e Programa de Reabilitação Urbana.

A salvaguarda e recuperação do património edificado - de que os centros históricos são parte integrante - constituem um dever para as entidades competentes e para populações que dele tiram usufruto (enquanto produtoras, consumidoras ou habitantes). Trata-se de preservar uma identidade e as memórias inscritas na paisagem urbana como elementos multifuncionais, consequência de práticas quotidianas com retrospetivas históricas muito variadas que sobrepondo-se, impondo-se ou justapondo-se, recriam, em cada momento, um território testemunho do passado, espaço de vida quotidiano e promessa do futuro.

O centro histórico de Coimbra constitui um desses lugares, onde a memória coabita com as constantes mutações que se vão operando através de uma orientação política de governação do tecido urbano que se reflete tanto no património construído como nas populações que dele usufruem. 


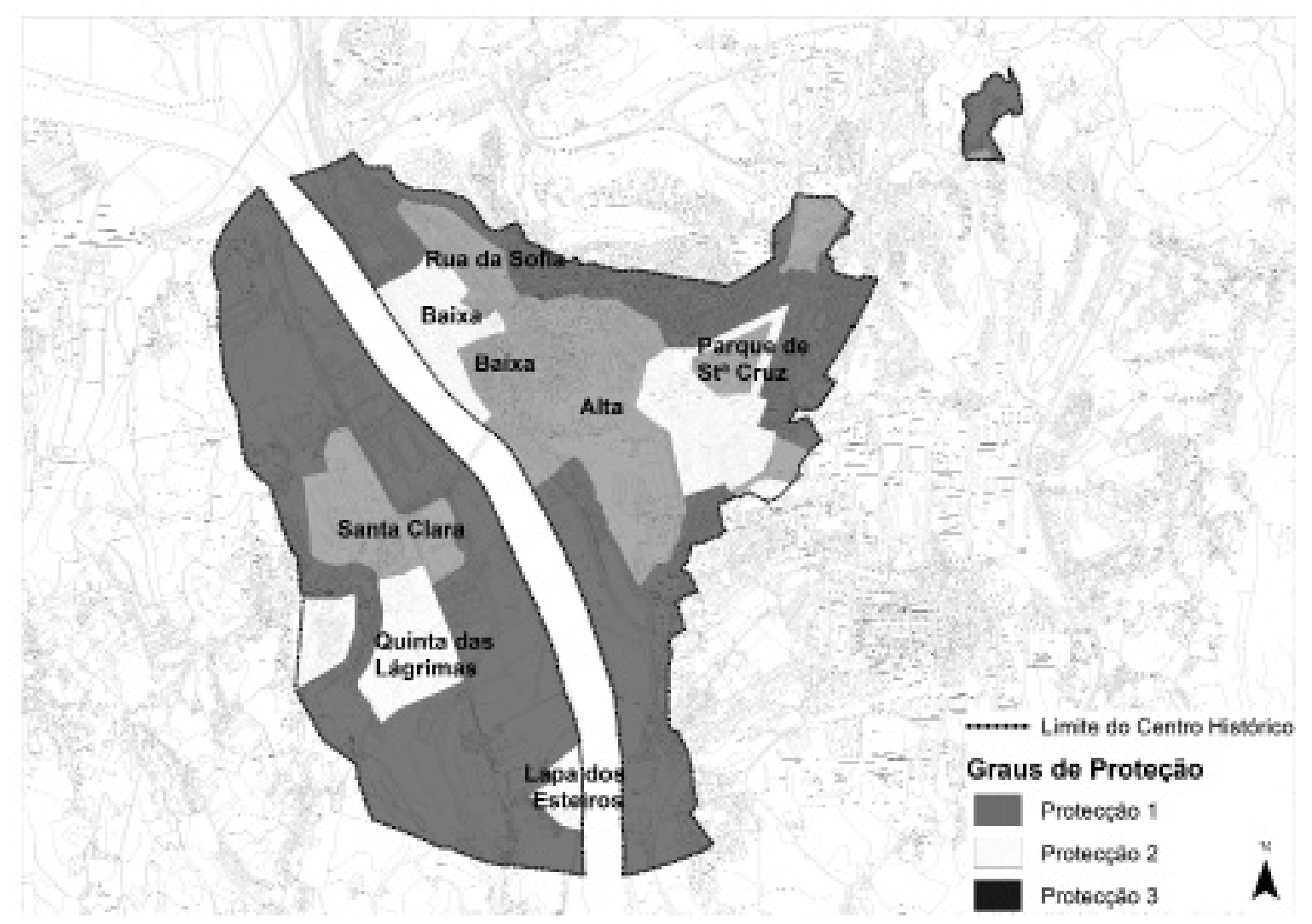

Figura 2 - Zonas de proteção do Centro Histórico de Coimbra Fonte: Adaptação própria. CMC

O centro da cidade de Coimbra integra edifícios e quarteirões de inegável valor patrimonial, objeto de preservação e proteção, tanto voluntarista como institucional, numa lógica de relação intensa entre responsabilidade e sustentabilidade. No entanto, a sua história é, também, elemento promotor de envelhecimento e de obsolescência de muitas das suas infraestruturas, equipamentos e população residente. Tudo isto concorre para uma progressiva degradação dos edifícios e para o agravamento das condições de vida, segurança e salubridade de espaços e pessoas. Estas circunstâncias obrigaram à prossecução de políticas intervenção urbanística que na Alta de Coimbra vieram a constituir a Área Crítica de Recuperação e Reconversão Urbanística (ACRRU) (Figura 3), de forma a inverter a contínua deterioração do património construído, possibilitando a reabilitação e renovação urbana da referida área.

Com a ACRRU a ser convertida em Área de Reabilitação Urbana (ARU) (Decreto-Lei ${ }^{\circ}$ 307/2009), o Município de Coimbra determinou iniciar o processo formal de definição de um instrumento próprio para a reabilitação urbana da Alta de Coimbra. Dentro dos limites da ACRRU do Centro Histórico consubstancia-se o "Projeto de Delimitação da Área de Reabilitação Urbana - Coimbra Alta" (2012) que engloba, para além da estratégia de reabilitação urbana, a visão para o centro histórico nos próximos anos.

Este documento estratégico estriba igualmente a delimitação de mais duas Áreas de Reabilitação Urbana, cujos programas de intervenção se encontram em elaboração: ARU Baixa (que inclui a área da Sociedade de Reabilitação Urbana e parte da área candidata a Património da Unesco - UC) e ARU Baixa-Rio. (Figura 4). Estas áreas de intervenção tiveram, ainda na sua base, os estudos levados a cabo pela Comissão Interdisciplinar da Baixa instituída em 2003, e que teve como funções o acompanhamento dos trabalhos de levantamento da Universidade de Coimbra (arquitetura, engenharia e sociologia), o plano de estrutura para os projetos a desenvolver no âmbito das Sociedades 


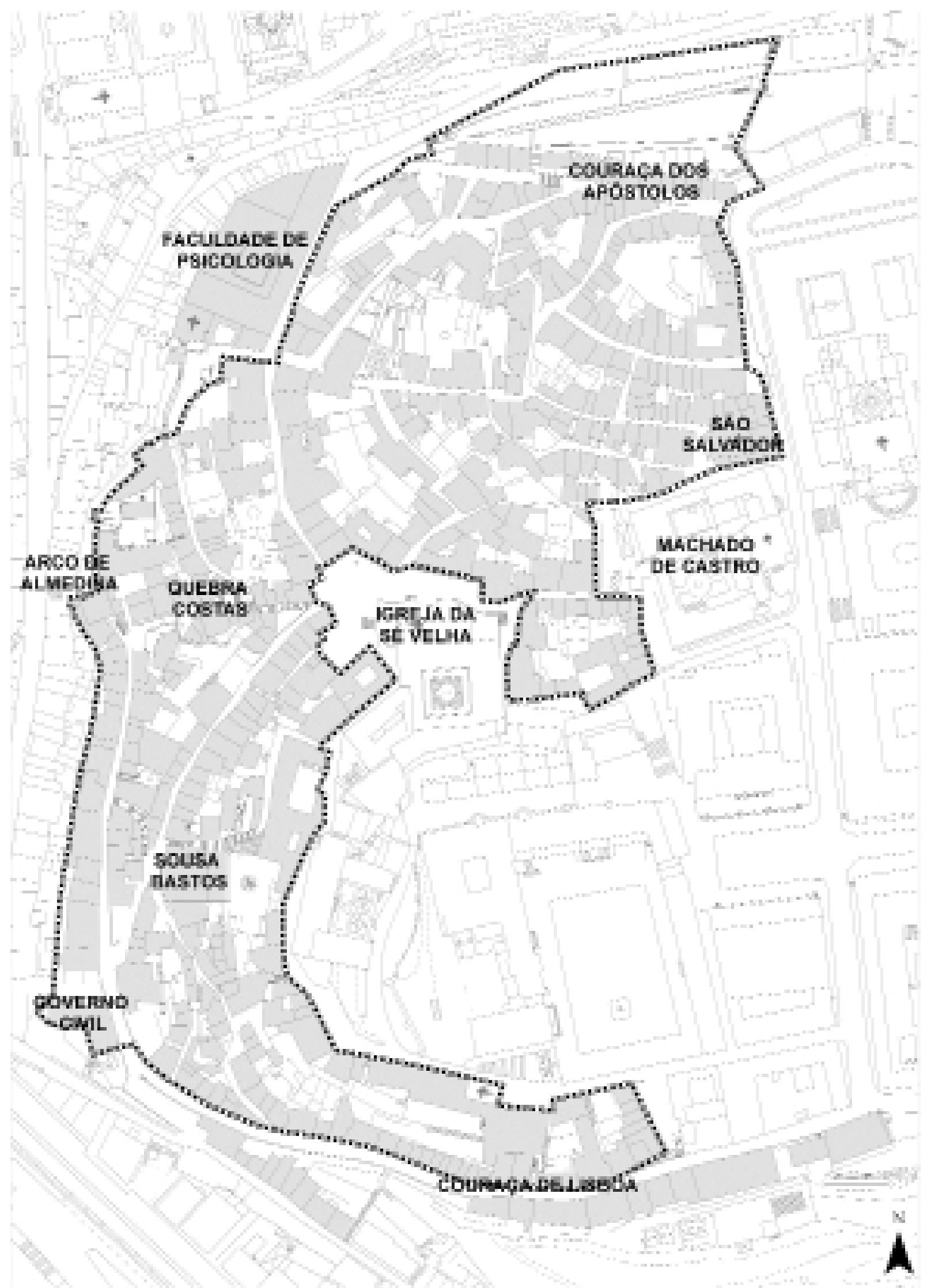

Figura 3 - Limites da ACRRU do Centro Histórico da Cidade de Coimbra (Decreto ${ }^{\circ}$ 44/2003, de 24 de Setembro).

Fonte: Adaptação própria. CMC 
de Reabilitação Urbana (SRU's) e o acompanhamento e dinamização de iniciativas de privados que tivessem intervenções para a zona.

Outro projeto de valor, com expressão urbanística e imagética para Coimbra é a Candidatura da Universidade de Coimbra a Património da Unesco (CUCPU), que nasce da conjugação de conveniências diversas, sendo a principal delas o facto de a universidade ser uma das mais antigas da Europa, um ex-libris da cidade de Coimbra e, até mesmo, de Portugal, sendo a sua atratividade turística assinalável e reconhecida. A presumível confirmação deste desiderato reforçará, sem dúvida, o valor de mercado e o prestígio que a Universidade de Coimbra goza no domínio turístico.

O centro histórico, zona antiga e sensível da cidade, habitada por uma população com características peculiares, objeto de intervenções diversas, se sujeita a uma maior pressão turística, exige que os recursos turísticos locais sejam integrados no planeamento urbano numa lógica de benefício mútuo. É imprescindível apostar na conceção e implantação de um sistema de gestão integrada dos recursos turísticos locais, de modo a tornar a oferta competitiva, a não defraudar as expetativas dos visitantes e a evitar que se lese o bem-estar e a qualidade de vida dos residentes.

Trata-se pois de um esforço conjunto Univer(sc)idade. Não sendo uma candidatura da cidade, especialmente devido à imagem associada à destruição, pelo Estado Novo, da Alta, procura-se que se identifique como tal, misturando diversos elementos que constituem as marcas de um lugar central como é Coimbra. Assim, dá-se relevância à Universidade, à história da cidade, à diferenciação do centro histórico entre Alta e Baixa, aos programas de requalificação urbana como a SRU, ao projeto do Metro Mondego e à candidatura de património imaterial que se confunde entre tradições académicas e tradições populares (festas académicas, festas da Rainha Santa, fado de Coimbra).

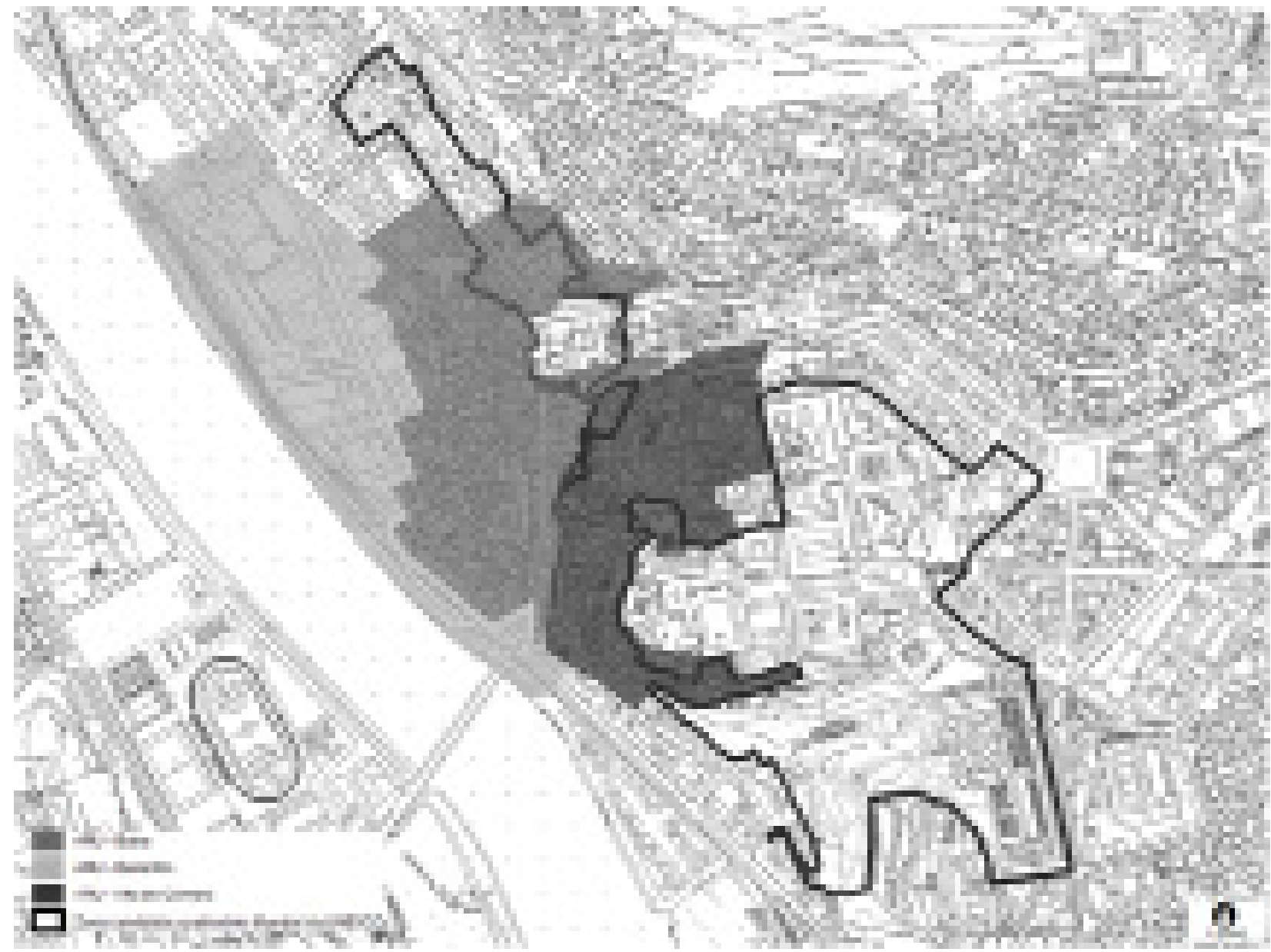

Figura 4 - Limite das Áreas de Reabilitação Urbana Fonte: Adaptação própria. CMC 
Ao longo dos anos, a perda de protagonismo do centro tradicional da cidade em detrimento de outras centralidades, levou ao seu esvaziamento. Reforçar Coimbra como centralidade nacional e regional e afirmá-la como cidade do conhecimento e da inovação, poderá passar, de acordo com este documento estratégico, por um

Centro Histórico valorizado e coeso, que se afirma como elemento central e unificador do sistema urbano policêntrico, fator de articulação das duas margens, elemento único de apropriação do Mondego pela cidade, que nele concentra grande parte da vida urbana e que valoriza e potencia a sua memória e o património cultural ... (PARQUE EXPO, 2012)

Perante a multiplicidade de relações entre os comércios tradicionais e as novas formas comerciais, associadas a outros lugares urbanos, fora do centro urbano original, a cidade torna-se policentrada e encontra em Celas, na Solum e no Vale das Flores centralidades complementares e especializadas que contribuem para uma outra organização da cidade.

Atendendo a esta realidade e tentando dar expressão ao significado superlativo do Centro histórico na cidade de Coimbra o documento de Estratégia de Reabilitação Urbana da Alta apresenta como visão o recentrar da cidade no seu centro histórico (Figura 5).

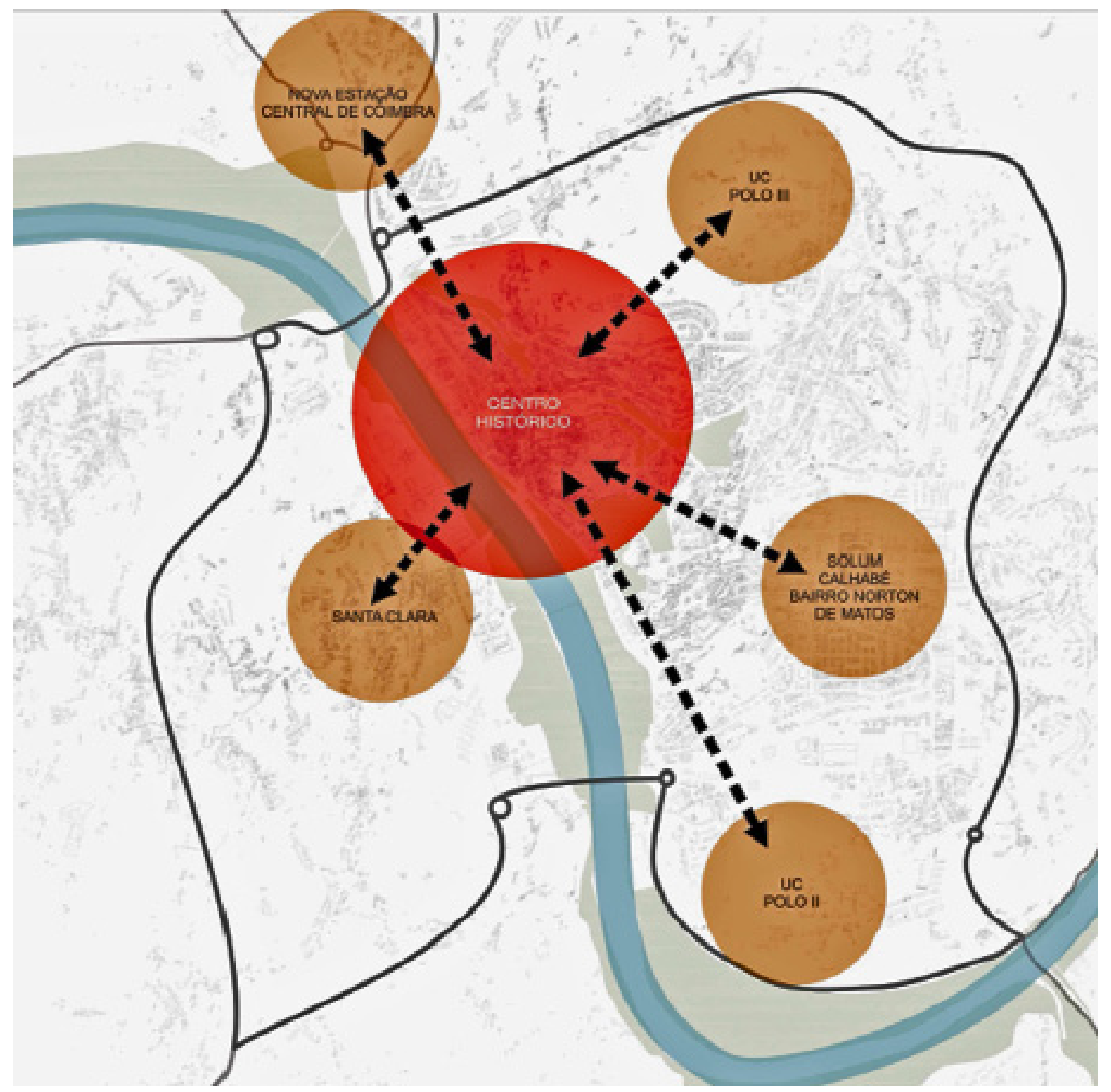

Figura 5 - Visão para o Centro Histórico de Coimbra - sistema urbano - Documento de Estratégia de Reabilitação Urbana.

Fonte: Parque Expo 
Para atingir este objetivo o documento define 6 eixos de intervenção estratégicos: densificar a multifuncionalidade; reforçar conexões e facilitar a mobilidade; valorizar a paisagem e consolidar a continuidade ecológica; valorizar o ambiente urbano; valorizar o património cultural; desenvolver o turismo.

\section{PROGRAMAS DE INCENTIVOS À REABILITAÇÃO URBANA}

As primeiras operações de reabilitação urbana em Portugal surgem nos anos 70, através do Decreto-Lei n. $.^{\circ} 8 / 73$, de 8 de Janeiro. Este diploma permitia que as autarquias e o então Fundo de Fomento da Habitação promovessem a realização de planos de reconversão para as áreas manifestamente degradadas.

Três anos mais tarde, o Ministério da Habitação, Urbanismo e Construção, através do Decreto-Lei n. ${ }^{\circ}$ 704/76, de 30 de Setembro, revogado pelo artigo $17 .^{\circ}$ do Decreto-Lei n. ${ }^{\circ}$ 220/83, de 26 de Maio, implementa o Programa de Recuperação de Imóveis Degradados (PRID), que previa que o Fundo de Fomento da Habitação dinamizasse um programa especial para a reparação de fogos ou imóveis em degradação, destinado à concessão de empréstimos e subsídios para obras de reparação, conservação e beneficiação do património habitacional nacional público e privado, urbano e rural.

Em 1986, através da Secretaria de Estado da Habitação, é lançado o primeiro Programa Público de Reabilitação Urbana, onde se consagrava o apoio do Estado à criação de Gabinetes Técnicos Locais. Em 1988, num contexto em que se sentia a necessidade de resultados foram criados os programas RECRIA e o PRAUD, ambos direcionados para a reabilitação do parque habitacional degradado. No início dos anos 90 e com vista à erradicação de barracas nas áreas metropolitanas de Lisboa e Porto é implementado o Programa Especial de Realojamento (PER).

Na década de 1990, , foram lançados dois outros programas de apoio à reabilitação de edifícios, o REHABITA e o RECRIPH que correspondiam a um alargamento do âmbito dos apoios à reabilitação, procurando colmatar situações não contempladas na legislação anterior. Mais recentemente foi criado o programa SOLARH, que começou devido à necessidade de apoiar pequenas reparações de casas habitadas fora das áreas urbanas, sendo posteriormente reformulado de forma a promover a reabilitação de todo o parque habitacional e estimular a colocação no mercado de fogos devolutos.

Estes programas foram, ao longo dos últimos anos, os principais instrumentos de apoio à reabilitação e realojamento sem que, no entanto, se tenham revelado suficientes para as necessidades que se faziam e fazem sentir.

Em Coimbra, os programas de apoio à reabilitação urbana tem tido alguma adesão, no entanto é no Centro Histórico que eles têm ganho cada vez mais expressão.

O PRAUD - Programa de Reabilitação de Áreas Urbanas Degradadas (Fig. 6) - tem como objetivo promover operações de reabilitação ou renovação de áreas urbanas degradadas, através de auxílios técnico-financeiros. Além do cariz instrumental que possui, através do apoio à criação dos Gabinetes Técnicos Locais, que culminou com a elaboração do Plano de Pormenor da Encosta Poente da Alta de Coimbra, apoia igualmente operações materiais de reabilitação e renovação de áreas urbanas degradadas.

No centro histórico o programa PRAUD-Obras está confinado à antiga ACRRU e, ao longo dos últimos anos, tem tido uma forte adesão, motivado em parte pelo trabalho feito pelo Município com a população local agindo como entidade facilitadora e impulsionadora do processo de reabilitação urbana. Em casos extremos, este trabalho tem-se desenvolvido através das vistorias realizadas que potenciam a imposição de obras de conservação. (Figura 7). 


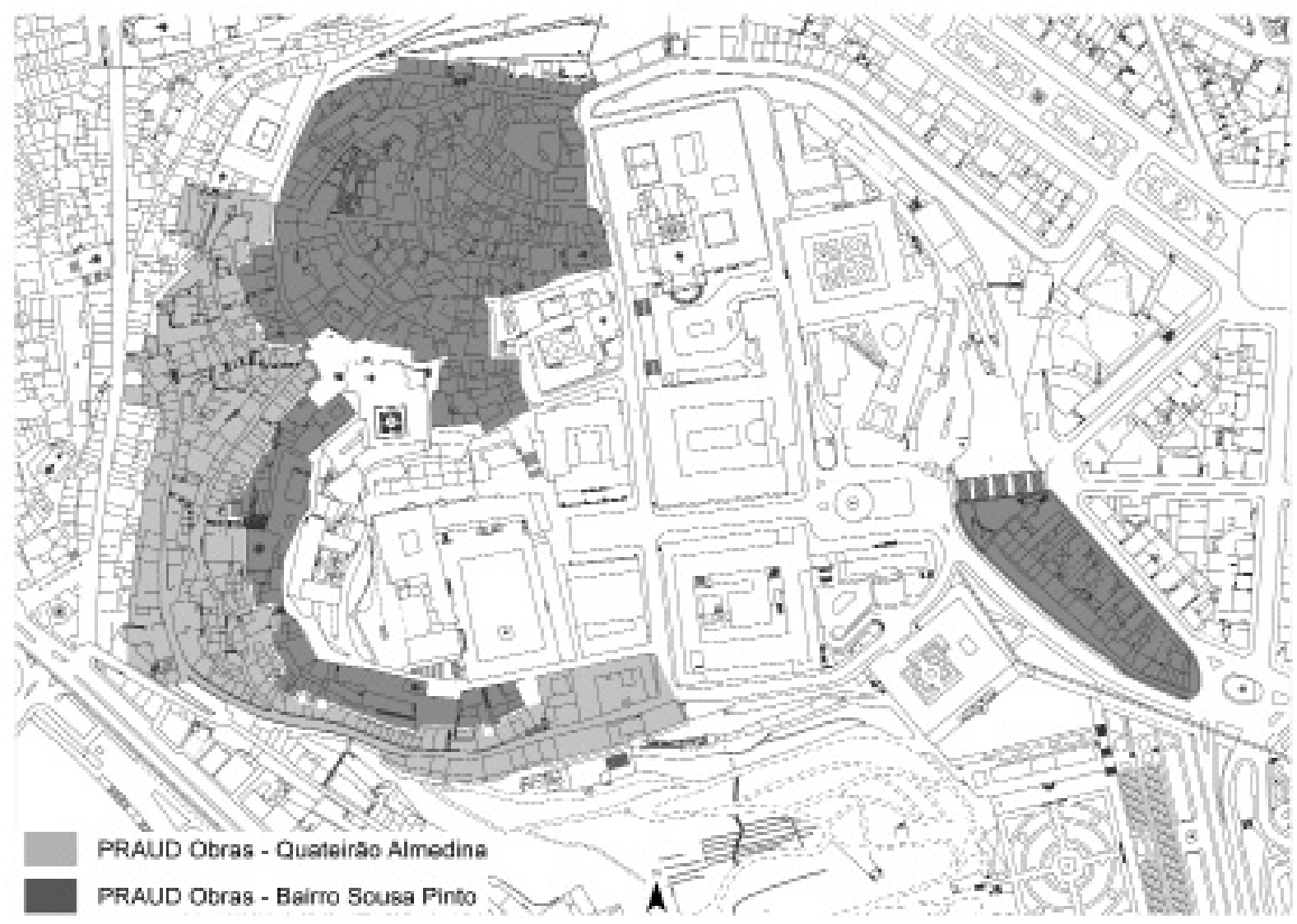

Figura 6 - Delimitação das áreas PRAUD

Fonte: Adaptação própria. CMC

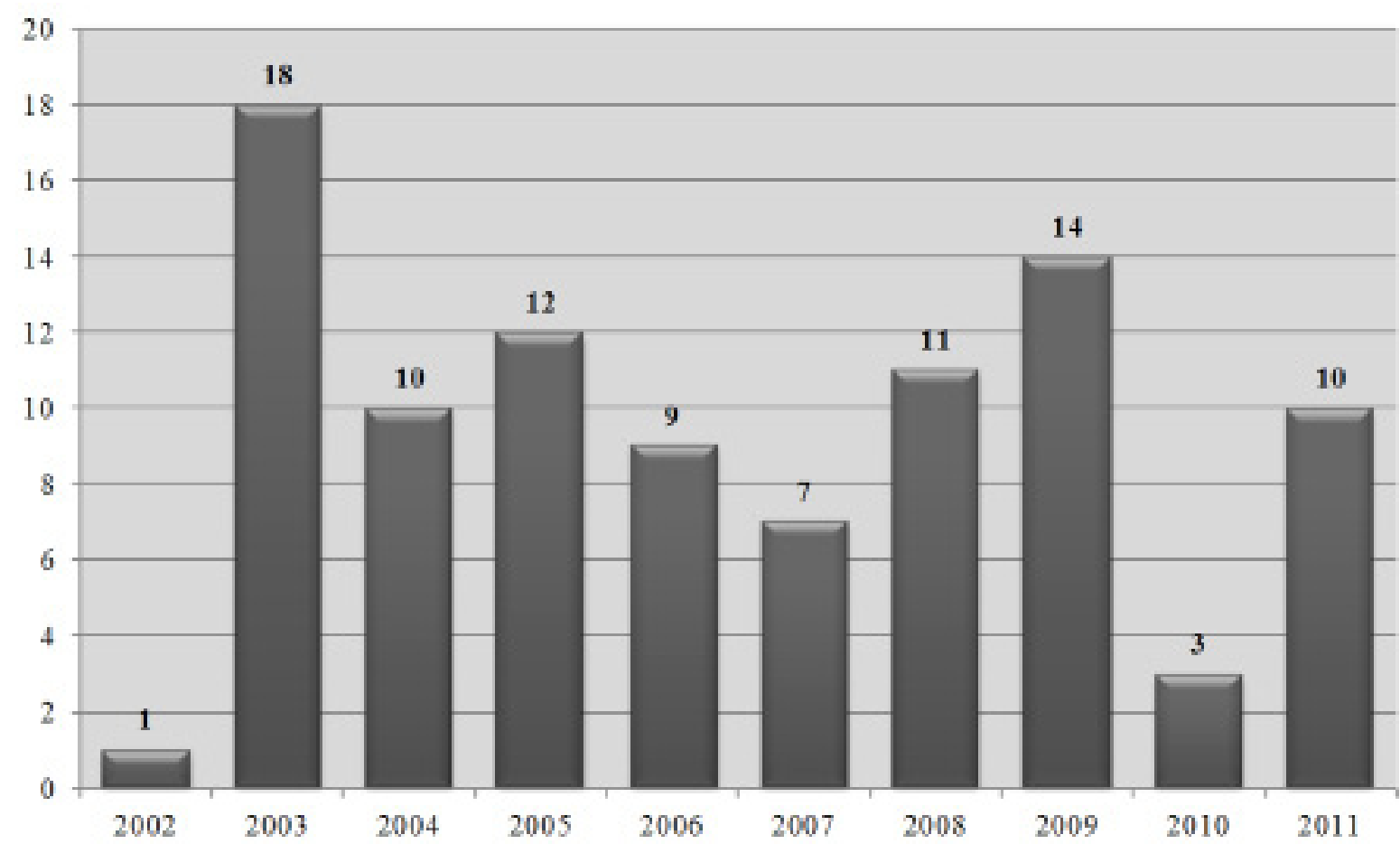

Figura 7 - Gráfico de Evolução das adesões ao Programa PRAUD/Obras Fonte: Adaptação própria. CMC 
Um outro programa municipal que tem tido forte adesão é o "Coimbra com Mais Encanto" que contribui com os materiais de pintura, cal ou tinta, destinadas ao tratamento das fachadas dos prédios. Neste caso, dá-se sempre prioridade aos edifícios que se apresentem, comparativamente, em pior estado de conservação e os beneficiários ficam também isentos da taxa de ocupação da via pública por andaimes/tapumes.

Paralelamente a estes programas existe também um conjunto de incentivos fiscais e financeiros, disponíveis e utilizáveis, que são capazes de diferenciar positivamente a recuperação do edificado, face à construção nova. Este conjunto de apoios estará sempre em aperfeiçoamento e atualização no quadro das novas políticas que eventualmente venham a ser definidas, sendo certo que, recentemente, através duma declaração do presidente do Instituto da Habitação e Reabilitação Urbana e tendo em conta a conjuntura económica que o país atravessa, todos os programas a fundo perdido deixam de existir fazendo com que seja necessário criar novas formas de reabilitação nos centros históricos.

Contudo, vários são os incentivos atualmente existentes tendo em conta a recuperação do parque habitacional, nomeadamente os benefícios fiscais, os Fundos de Investimentos Imobiliário, o Imposto de Valor Acrescentado à taxa reduzida, a isenção do Imposto Municipal sobre Imóveis (IMI), o Imposto Municipal sobre Transmissões Onerosas de Imóveis para prédios reabilitados entre 2008 e 2020 e ainda a aplicação de uma minoração de $10 \%$ da taxa de IMI aos prédios urbanos inseridos nas freguesias de $\mathrm{S}$. Bartolomeu e Almedina e nos prédios arrendados em toda a área do município. A tudo isto junta-se ainda a isenção de taxas, até Dezembro de 2013, nas operações urbanísticas sujeitas a licenciamento, informação ou comunicação prévia e autorização de utilização em imóveis localizados no Centro Histórico.

\section{OUTROS ESPAÇOS, A MESMA CIDADE HISTÓRICA. OS ESPAÇOS VERDES COMO ÁREAS DE ATRAÇÃO E DE ORDENAMENTO URBANO}

Os espaços verdes que são, antes de mais, lugares de lazer e de socialização fazem cada vez mais parte do nosso imaginário. Estes espaços possibilitam uma harmonia dos cidadãos com o seu bairro, com a sua cidade. A falta destes espaços gera sentimentos de repulsa por parte dos habitantes e são, claramente, associados à qualidade de vida.

Os espaços verdes tornam os lugares em espaços com valor acrescido. Para além dos tempos de trabalho e emprego que os espaços construídos normalmente constituem, e dos espaços de circulação que funcionam como modo de acessibilidade mas normalmente associados, nas áreas urbanas, a pressões e tensões relacionadas com o tempo que neles se despende, o espaço verde permite-nos valorizar outros tempos sociais. Os jardins, as matas, os parques acabam por criar, a quem os visita, um sentimento de fuga à rotina, de acesso a um tempo livre, tempo de prazer e mesmo de lazer, quando os equipamentos adequados se encontram presentes. As pessoas estabeleçam ligações fortes com estes espaços, surgindo como um modo agradável das pessoas se apropriarem do espaço público. Hoje, as intervenções no centro histórico de Coimbra têm ido no sentido de dar prioridade ao peão. A criação de ruas pedonais e as políticas de restrição de acessibilidade automóvel têm estado presentes nas opções políticas do centro histórico urbano. Todavia, o ordenamento urbano tem beneficiado da criação de novos espaços verdes, promovendo a qualificação das áreas onde são criados, atribuindo ao solo um valor acrescido, em termos de renda fundiária, mas também em termos sociais, porque possibilitam o repouso, o encontro e o recreio, e são também potenciadores de atividades de sustentabilidade territorial, na medida em que possibilitam o controlo microclimático, o equilíbrio do ciclo hidrológico, fixa as poeiras e melhora a qualidade do ar.

$\mathrm{O}$ que tem acontecido em Coimbra e sobretudo no centro histórico é uma crescente preocupação com a criação de espaços de lazer e espaços verdes. O Programa POLIS foi, sem dúvida, o ponto de viragem, requalificando urbanisticamente uma área de aproximadamente 80 hectares, tendo como elemento ambiental o Rio Mondego, numa área que faz parte da cidade histórica ou 
que contacta com ela diretamente . Centrar a cidade no rio e promover a aproximação efetiva das duas margens foi a premissa que permitiu criar um parque verde urbano multifuncional vocacionado para a animação, recreio, educação e desporto com um enquadramento paisagístico ambiental e patrimonial de qualidade: o Parque Verde do Mondego.

A margem direita é constituída por uma área de mais de $400.000 \mathrm{~m} 2$, basicamente dedicada ao lazer, com uma ampla zona de esplanadas, assentes numa plataforma de madeira sobre o rio. A zona verde soma quatro quilómetros de corredores para peões e o mesmo comprimento de ciclovias, por entre pavilhões com exposições temporárias, dos quais se destaca o Pavilhão Centro de Portugal, que foi o Pavilhão de Portugal da Expo 2000, em Hannover, projetado por Souto Moura e Álvaro Siza Vieira. Ainda na margem direita destaca-se a recuperação e dinamização do antigo edifício da estação de captação de água, através da criação do Museu da Água e do Centro de Interpretação Ambiental.

A ligação entre as duas margens faz-se através da ponte pedonal "Pedro e Inês", inaugurada em 2006 e hoje um ex-libris da cidade.

Na margem esquerda foram construídas diversas estruturas que permitem a prática de desporto (canoagem, remo, vela, entre outros), de atividades de lazer (um parque de merendas, as piscinas municipais descobertas), de diversão infantil. O espaço revitalizado pelo programa POLIS possibilitou também recuperar, reinventar e recriar atividades trazendo a estes espaços verdes e de lazer, a Feira Popular, a Queima das Fitas (agora com mais espaço e melhores instalações), a Feira sem Regras, a Feira de Artesanato, a Feira do Livro, entre outras. Paralelamente, mas não menos importante, surge a recuperação do Mosteiro de Santa Clara-a-Velha a que foi associado um centro interpretativo permitindo fazer das margens do rio, um espaço verde e de lazer por excelência, que terá, a muito breve trecho, no Rossio de Santa Clara (a cidade histórica da margem esquerda), a refuncionalização e reabilitação do Convento de São Francisco, futuro Centro de Congressos da cidade de Coimbra.

\section{OUTROS ESPAÇOS, A MESMA CIDADE HISTÓRICA. ESPAÇOS SOCIAIS, CULTURAIS E DE LAZER}

Como deu para perceber, os espaços verdes integram investimentos significativos em termos sociais, culturais e de lazer. Todavia, não é possível deixar de fazer referência a toda a riqueza ao nível dos monumentos e museus e até mesmo de espaços/lugares capazes de potenciar o turismo cultural e o lazer, criando bases para um processo de revitalização do centro histórico.

É importante integrar novos equipamentos e serviços, não só direcionados para o turismo, mas também para a população local. Coimbra reclama ser uma cidade de cultura. Certamente que o é, na exata medida que historicamente a cultura portuguesa ficaria amputada e não poderia ser entendida sem olhar à contribuição fundamental de Coimbra.

No entanto, para que esse papel relevante na cultura nacional continue a existir devem ser criados equipamentos culturais que projetem, no campo cultural, a centralidade regional e nacional a Coimbra e promovam turisticamente a cidade.

São vários os projetos que já iniciaram ou irão iniciar em breve e que, com certeza irão beneficiar a cidade a este nível. A recuperação da Ala Central do antigo colégio das Artes no Pátio da Inquisição para a instalação da Cena Lusófona - Associação Portuguesa para o Intercâmbio Teatral, pretende alargar a oferta e valorizar culturalmente a cidade. Paralelamente, a inclusão da cidade de Coimbra na Rede Urbana dos Castelos e Muralhas Medievais do Mondego permitirá que na Torre de Anto (monumento nacional) se instale o Museu da Guitarra e do Fado. Com este projeto, pelas valências que irá gerar, pela sua inserção na muralha da cidade e consequentemente no Núcleo da Cidade Muralhada, pelo património histórico que a envolve, pela dignificação que irá dar ao Fado de Coimbra e ao espólio do Mestre Carlos Paredes, contribuirá significativamente para a organização dos produtos turísticos. 
A recuperação e criação de um centro interpretativo no Mosteiro de Santa Clara-a-Velha promoveram a cidade para além dos seus limites. $\mathrm{Na}$ verdade, todo o projeto que envolveu a recuperação do Mosteiro, que esteve submerso durante décadas, potenciou um incremento de visitantes à cidade.

Paralelamente à criação de espaços de cultura e lazer foram ou irão ser recuperados espaços, alguns deles emblemáticos, com um único objetivo, o social. Muitos destes espaços são e serão uma mais-valia na medida em que promovem a fixação de população nestas zonas mais desertificadas e onde os equipamentos escasseiam. Assim sendo, o Centro de Noite "Telha Amiga" na baixa da cidade constitui um importante projeto social de apoio à terceira idade e de combate à pobreza e à solidão deste grupo etário e ao mesmo tempo de reabilitação de um edifício com características medievais que se encontrava em ruínas.

Um outro equipamento a ser criado em pleno centro histórico servirá uma população mais jovem, respondendo às necessidades dos casais jovens. $\mathrm{O}$ equipamento proposto, creche com berçário e jardim-de-infância vai receber crianças desde os 4 meses até aos 5 anos e servir de pólo de atração para uma zona envelhecida. Tratando-se de um equipamento de proximidade e pretendendo revitalizar a Alta, a localização proposta não poderia ser mais central, ocupando um edifício no Largo da Sé Velha.

Aquilo que também temos vindo a assistir é a uma mudança de paradigma no que respeita aos equipamentos hoteleiros. Temos assistido em Coimbra à implantação de um novo conceito de alojamento, nomeadamente os hostel's (um deles já acima referido) onde os preços são mais acessíveis e onde há uma mais fácil socialização entre os hóspedes. No último ano abriram 4 hostel's em Coimbra, sendo que 3 deles estão localizados no centro histórico da cidade.

Estas novas atividades e algum despovoamento noturno deste centro histórico urbano criam, pelo menos em termos de perceção, alguma insegurança. Todavia, a segurança de pessoas e bens constitui-se como um fator chave em qualquer núcleo urbano. Um clima de insegurança gera psicologias de fuga, sendo por isso necessário criar formas de impedir a fuga da população do centro e de diminuir a criminalidade. No centro histórico de Coimbra está a funcionar, desde 2009, um sistema de videovigilância composto por 17 câmaras (12 para vigilância das pessoas e tráfego e 5 apenas para o tráfego) que funciona das $21 \mathrm{~h} 00$ até às $7 \mathrm{~h} 00$, num espaço grosso-modo triangular e que vai do Largo da Portagem à Praça 8 de Maio, à urbanização da Loja do Cidadão, passando pela Av. Fernão de Magalhães e pela Av. Emídio Navarro.

\section{ACESSIBILIDADES}

A acessibilidade aos centros históricos é um dos seus principais constrangimentos e as dificuldades associadas às plantas irregulares, de ruas estreitas, pavimentos desiguais, são concatenadas a uma densificação de construção e a espaços e monumentos patrimonializados que obrigam a cuidados redobrados na intervenção urbanística. À problemática acessibilidade espacial, a perceção da população junta uma acessibilidade psicológica repulsiva, associada a ambientes sociais onde surgem situações de exclusão ou deficiente integração social e económica. Na verdade, é cada vez mais difícil chegar ao centro porque "as ruas não chegam para os carros, os carros prejudicam os peões, o estacionamento não chega” (PORTAS, 1981). Todavia, também é cada vez menos frequente querer chegar ao centro, porque outras áreas centrais com acessibilidades acrescidas e serviços e comércios organizados, em ambientes mais controlados, se tornam mais atrativos para a população.

De facto, é urgente tornar o centro mais acessível a toda a população eliminando as interferências do tráfego de passagem, criando uma ambiência atraente e oferecendo a rua às pessoas. Tornar o espaço dos centros históricos mais aberto, mais animado e mais virado para o transeunte é fundamental para conseguir atribuir valor ao centro histórico.

Neste sentido, em termos de acessibilidade espacial, a CMC tem feito investimentos significativos no sentido de tornar este centro disponível para a população. Esse desiderato tem sido conseguido com restrições ao tráfego automóvel em alguns mosaicos da cidade. Este processo foi 
iniciado em 1993 com a pedonalização das Ruas Ferreira Borges e Visconde da Luz, que todavia não foi acompanhada com o investimento adequado em termos de funções centrais (atividades lúdicas, animação, esplanadas, artesanato, lojas franchisadas). As restrições de acesso à área da Baixinha tornam também essa área num espaço comercial a céu aberto. Porém, a ambiência da rua (irregular, estreita, com algumas atividades para-legais) condiciona frequentemente a circulação da população pouco habituada a circular nessas áreas.

Em relação aos meios de transporte, os transportes públicos precisam de chegar tão perto quanto possível das áreas mais movimentadas do centro das cidades e uma vez que não é de esperar que a posse e uso de automóvel diminua num futuro próximo, é também necessário planear áreas de estacionamento ou de restrição a populações não residentes.

Em 2002, a criação das zonas de estacionamento de duração limitada e as zonas de acesso condicionado (ZAC) ao trânsito automóvel à Baixa e Alta de Coimbra funcionaram como limitador de acessibilidade rodoviária. Para aceder ao estacionamento a população precisa de adquirir um cartão de residente que garante condições especiais de estacionamento aos residentes nas Áreas de Estacionamento (AE) criadas pelo Regulamento Geral das Zonas de Estacionamento de Duração Limitada.

Existe também o Elevador do Mercado, inaugurado em 2001, que liga a Rua Olímpio Nicolau Rui Fernandes (junto ao Mercado Municipal D. Pedro V) à Rua Padre António Vieira atenuando o problema das acessibilidades entre a Baixa e a Alta, tendo em conta os níveis topográficos tão distintos. $\mathrm{O}$ acesso a este elevador é gratuito para todos os munícipes recenseados na Alta e para cidadãos com mais de 60 anos.

Na Alta de Coimbra, foi também introduzido um novo conceito de transporte público, com miniautocarros movidos a energias limpas, o que permitiu, desde logo, o condicionamento da circulação e estacionamento automóvel nesta zona da cidade.

A Linha Azul, ou Pantufinhas, como carinhosamente é chamado pelos habitantes, faz a ligação entre a Alta e a Baixa, sendo gratuito para os residentes da freguesia de Almedina.

Paralelamente foram sendo construídos parques de estacionamento (alguns subterrâneos) ao redor do centro da cidade e mesmo no centro histórico, nomeadamente o parque de estacionamento do mercado municipal, do Bota-Abaixo, da Cerca de Santo Agostinho e os do Parque Verde do Mondego.

Estes parques e restantes zonas de estacionamento poderiam ser um fator de atração significativo se fosse criado um sistema de tempo gratuito de estacionamento na primeira hora para quem se deslocasse à Baixa.

Algumas artérias do centro histórico foram, ou estão a ser intervencionadas com obras de repavimentação, ainda que na maior parte delas, complementem não apenas a vertente das acessibilidades para todos, com melhores acessos para pessoas com mobilidade reduzida, mas também na vertente das infraestruturas (gás natural, TV cabo, rede de águas pluviais e residuais e rede elétrica) e noutros casos uma intervenção paisagística. Nestes casos estão por exemplo a Couraça dos Apóstolos, a rua da Alegria, a rua Corpo de Deus, o Arco de Almedina, o bairro Sousa Pinto na zona universitária.

\section{CONSIDERAÇÕES FINAIS}

Em sentido lato, cidade significa sempre produção, a vários níveis e numa multiplicidade de áreas e setores. Significa igualmente a produção contínua de espaço de vivência, diversidade, segurança, assimilação cultural e procura de consenso permanente entre os múltiplos parceiros envolvidos (desde o residente ao poder autárquico).

Ora tal filosofia só é possível se num processo de intervenção (espacial ou sectorial) todos os agentes possam contribuir e ver salvaguardada a sua participação. Reabilitar uma cidade, apostando na proximidade com as pessoas que a vivenciam é apostar na participação de todos os que a 
constituem. Conceber o direito à participação e a expressão de opiniões, à de defesa dos interesses, dos modos e dos hábitos de vida é fundamental enquanto visão de projetos de intervenção urbana e incontornável enquanto metodologia para atingir as metas planeadas. Os habitantes, os comerciantes, os grupos sociais, as diversas associações, os turistas, são, todos eles, intervenientes no processo de reabilitação da baixa de Coimbra, do centro histórico, da própria cidade.

A Baixa, centro comercial a céu aberto por excelência, tem tentado, ao longo dos anos, criar sinergias com os diferentes públicos, quer através de iniciativas de cariz comercial, quer através da implementação de políticas/projetos capazes de reabilitar/revitalizar uma área de excelência. Fê-lo através do projeto diversos, tanto de cariz público como de cariz privado e em parceria. A Empresa Municipal de Turismo teve um papel determinante nestas parcerias. De igual modo, a Associação para a Promoção da Baixa de Coimbra (APBC) que se assume como um Condomínio Comercial e apresenta como slogan "Uma Nova Visão para a Baixa". São organizadas algumas iniciativas capazes de trazer população à Baixa, ainda que, na maior parte das vezes, estas ações não consigam ter o efeito desejado, em primeiro, por não haver por parte dos comerciantes a adesão desejada, em segundo, porque apesar destas ações conseguirem trazer população à baixa, esta vinda é feita apenas e só devido àquele evento.

Por seu lado, a CMC, especialmente através do seu Gabinete para o Centro Histórico, tem promovido um conjunto de programas que importa identificar. O projeto URBE VIVA tem como objetivo estudar a revitalização de áreas económicas centrais, concretamente através de um apoio direto ao comércio tradicional, com a troca de experiências e boas práticas entre cidades onde se incluem Bolonha, Veneza, Pádua, Patras e Santa Cruz de Tenerife. Em Coimbra, o importante foi perceber o modo de salvaguardar o comércio tradicional presente em áreas como a Baixa da Cidade perante a capacidade de atração, ação, animação e gestão das novas formas comerciais, como são as grandes superfícies e os centros comerciais.

O Programa de Apoio à Modernização do Comércio (PROCOM), criado em 1994, mais tarde redenominado URBCOM (Sistema de Incentivos a Projetos de Urbanismo Comercial), visou a revitalização de certas zonas de forte atividade comercial mas que se encontram em declínio.

O projeto VALUO tinha por objetivo analisar o mercado imobiliário na zona histórica de Coimbra e os efeitos nela induzidos pelas intervenções urbanísticas ao abrigo dos diferentes programas de reabilitação urbana, conduzidas pelas entidades públicas. Através deste projeto percebeu-se que, no período de 2003 e 2005, houve um ligeiro crescimento do preço médio por $\mathrm{m} 2$ da habitação no continente face ao valor registado em Coimbra (7,9\% contra 7,1\%). Ainda assim, no final do período, o m2 da habitação em Coimbra era 17\% mais elevado do que o do Continente.

O eixo Quebra-Costas, que parte do Arco de Almedina e vai até à universidade, passando pela Sé Velha, tem sido uma das zonas do centro histórico onde se tem verificado um grande dinamismo/ diversidade comercial. A maioria dos estabelecimentos comerciais que abriram nos últimos anos, apostaram na promoção das artes, da cultura, do turismo, na marca de Coimbra, através, por exemplo, do artesanato e da canção de Coimbra. Paralelamente, estes comerciantes, uniram-se e realizam, uma vez por mês, uma festa designada "mercado Quebra- Costas" cujo principal objetivo é a par da mostra e venda de produtos de artesanato urbano, livros, discos e vinis, venda e prova de produtos gastronómicos, propor um programa de atividades de âmbito artístico, cultural e turístico, numa perspetiva multidisciplinar, entendendo o espaço urbano como um espaço para o diálogo permanente, aberto à experimentação artística e à participação de todos. O último investimento efetuado permite a localização neste trecho da cidade de um estabelecimento hoteleiro (Hostel Serenata, em 2012), que permitirá uma maior proximidade do turista a este espaço histórico de Coimbra. Esta estratégia, de fazer participar o visitante no quotidiano e em atividades no centro histórico, com a recriação de experiências diversas, é fundamental para a qualificação deste espaço de grande densidade simbólica da cidade de Coimbra. 


\section{REFERÊNCIA BIBLIOGRÁFICA}

APBC - Agência para a Promoção da Baixa de Coimbra (Baixa ConVida) http://www.baixadecoimbra.com ASCHER, François (1998) - Metapolis - Acerca do futuro da cidade, Oeiras, Portugal, Celta

BALSAS, Carlos José Lopes (1999) - Urbanismo Comercial em Portugal e a Revitalização do Centro das Cidades. Lisboa, GEPE, 179 p.

BALSAS, Carlos José Lopes (2002) - O urbanismo comercial e as parcerias público-privado: para a gestão do centro das cidades ensinamentos da experiência estrangeira. Lisboa, Observatório do Comércio, 164 p.

C.M.C. - Câmara Municipal de Coimbra, http://www.cm-coimbra.pt

CAMAGNI, Roberto (1992) - Principes et modèles de l'économie urbaine. Paris, Económica. Association de Science Régionale de Langue Française. Biblioteque de Science Régionale.

CÂMARA MUNICIPAL DE COIMBRA (1993) - Urbanismo. Coimbra: Anos 90. Coimbra. Divisão de Planos da Câmara Municipal de Coimbra, 84 p.

COSTA, Eduarda Marques da (2002) - Cidades médias: contributos para a sua definição. Finisterra: Revista Portuguesa de Geografia,- No 74 (2002), p. 101-128

LAJUGIE, Joseph (1973) - Les Villes Moyennes. Paris, Éditions Cujas, 216 p.

MINISTÉRIO DO AMBIENTE E DO ORDENAMENTO DO TERRITÓRIO e Câmara Municipal de Coimbra (2001) - Viver Coimbra: programa Polis: plano estratégico. Lisboa, M.A.O.T., Programa Polis, 67 p.

PARQUE EXPO (2012) - Coimbra Alta - Área de Reabilitação Urbana, Volume A - Estratégia de Reabilitação Urbana, Parte I - Visão para o Centro Histórico

PARQUE EXPO (2012) - Coimbra Alta - Área de Reabilitação Urbana, Volume A - Estratégia de Reabilitação Urbana, Parte II - Estratégia de Reabilitação Urbana

PNPOT (2007) Programa Nacional de Políticas de Ordenamento do Território - Relatório. Anexo à Lei n57/2007, de 4 de Setembro, que aprova o Plano Nacional de Políticas de Ordenamento do Território, retificado pela declaração n ${ }^{\circ} 80-A$, de 7 de Setembro de 2007 e nº3-A, de 2 de Novembro de 2007. Obtido em 24 de setembro de 2012 de http://www.territorioportugal.pt/pnpot/Storage/pdfs/PNPOT_RELATORIO.pdf PORTAS, Nuno (1981) - Conservar renovando ou recuperar revitalizando com nota introdutória Sobre o Programa "Coimbra Antiga" por Matilde de Sousa Franco. Publicação no âmbito do Programa "Coimbra Antiga e a Vivificação dos Centros Históricos". Coimbra, Museu Nacional machado de Castro, 22 p.

REIS, José (2009) - O Paradoxo de Coimbra: relações inter-territoriais e espaço público. Arquitectura 21, 6, p. $62-63$

REYNAUD, Alain (1981) - Société, espace et justice: inégalités régionales et justice socio-spatiale, Presses Universitaires de France, Paris, 263 p.

SMTUC - Transportes Urbanos de Coimbra, http://www.smtuc.pt

TOBELEM-ZANIN, Christine (1995) - La qualité de la vie dans les villes françaises, Univ. Rouen Havre, $288 \mathrm{p}$.

Trabalho enviado em março de 2013

Trabalho aceito em abril de 2013 